\title{
Biomass of a Psychrophilic Fungus as a Biocatalyst for Efficient Direct Esterification of Citronellol
}

\author{
Mateusz Kutyła $^{1} \cdot$ Mariusz Trytek $^{1}$ [1] $\cdot$ Katarzyna Buczek $^{1} \cdot$ Ewa Tomaszewska $^{2} \cdot$ Siemowit Muszyński $^{3}$
}

Received: 2 February 2021 / Accepted: 30 April 2021 / Published online: 20 May 2021

(c) The Author(s) 2021

\begin{abstract}
A biomass-bound lipase from psychrophilic Chrysosporium pannorum A-1 is an efficient biocatalyst for direct esterification of $\beta$-citronellol and acetic acid in an organic solvent. The biomass is effectively produced by fungal submerged culture at $20{ }^{\circ} \mathrm{C}$, which results in lower energy consumption during the production of biocatalyst. Supplementation of the culture medium with calcium carbonate together with olive oil contributed to a significant increase in the active biomass of mycelium in one batch culture and increased the efficiency of the biocatalyst. Biomass-bound lipase showed high catalytic activity in a broad temperature range of $30-60^{\circ} \mathrm{C}$ and stability up to $70^{\circ} \mathrm{C}$. A maximum molar conversion value of $98 \%$ was obtained at $30^{\circ} \mathrm{C}$ in $n$-hexane using a 2:1 alcohol-to-acid molar ratio and $3 \% \mathrm{w} / \mathrm{v}$ of the biocatalyst within $24 \mathrm{~h}$. The high equimolar concentration of the substrates $(200 \mathrm{mM})$ did not have an adverse effect on mycelial biomass activity. Dry mycelium of $C$. pannorum is a promising biocatalyst for large-scale biosynthesis of citronellyl acetate, given its low-cost production, high activity at low temperatures, and reusability in a minimum of seven 24 -h biocatalytic cycles.
\end{abstract}

Keywords Biomass · Biomass-bound lipase $\cdot$ Esterification $\cdot$ Chrysosporium $\cdot$ Citronellyl acetate $\cdot$ Psychrophiles

\section{Introduction}

Esters of terpene alcohols, especially acetate esters, are valuable compounds in the flavor and fragrance industry, which was valued at 24.9 billion USD in 2014, with a predicted growth rate from 5 to $6 \%$ per year [1-3]. These compounds can be obtained via extraction from plant sources, chemical synthesis, or enzymatic biotransformation. It is difficult to obtain a large quantity of terpene esters from plant material due to the small amount of these compounds in essential oils and the hydrolysis of natural esters [4]. Chemical synthesis is

Mariusz Trytek

mariusz.trytek@umcs.pl

1 Department of Industrial and Environmental Microbiology, Faculty of Biology and Biotechnology, Institute of Biological Sciences, Maria Curie-Skłodowska University, Akademicka 19, 20-033, Lublin, Poland

2 Department of Animal Physiology, Faculty of Veterinary Medicine, University of Life Sciences in Lublin, Akademicka 12, 20-950, Lublin, Poland

3 Department of Biophysics, Faculty of Environmental Biology, University of Life Sciences in Lublin, Akademicka 13, 20-950, Lublin, Poland characterized by formation of a racemic mixture of products and often generates adverse environmental conditions [5]. A good alternative for the preparation of "natural" terpene esters is the enzymatic esterification of terpene alcohols and carboxylic acids using lipases. Compounds produced in this way can be referred to as "natural" in accordance with the provisions of the European Union and the USA [6]. However, isolated and purified enzymes are quite costly even with large-scale production.

Lipases (EC 3.1.1.1) are an important class of serine hydrolytic enzymes. They are widely used in food, detergent, textile, pharmaceutical, leather, and cosmetic industry $[7,8]$. They are synthesized by all living organisms: plants, animals, and microorganisms. Lipases have broad substrate specificity while maintaining their regioselectivity and stereoselectivity as well as a catalysis mechanism in which no cofactors are involved [9]. Lipases catalyze the hydrolysis of ester bonds in the water environment and a reverse reaction in an organic solvent and water deficiency conditions $[10,11]$. This property is suitable for the biocatalytic production of terpene alcohol, glucose, or flavonoid esters [12-14]. Bacterial and fungal lipases, most often used in this bioprocess, are usually secreted outside cells [15]. Therefore, to be suitable for multiple applications, the enzyme from the post-culture liquid must be concentrated, purified, and often 
immobilized on an appropriate carrier. These operations are usually associated with high costs of obtaining a pure preparation, substantial energy consumption, and loss of biocatalytic activity. An alternative source of an immobilized biocatalyst for esterification reactions is the intracellular lipase linked to the cellular hydrophobic membrane [16-18]. It has the basic features of immobilized biocatalysts, including stabilization of the protein structure, which increases their thermostability and resistance to denaturing factors, and easy separation from the reaction mixture after the bioprocess [19, 20].

From the point of view of environmental protection, the biocatalytic esterification of alcohols with carboxylic acids is the best way to obtain esters, as only water is the by-product of the reaction. However, the water formed during the process changes the equilibrium of the reaction towards hydrolysis [21]. Also, according to some reports, free acetic acid has a negative effect on lipase activity [22-24]. Therefore, despite the availability of many commercial lipases, there is still a need for new sources of lipases that will be efficient biocatalysts of direct esterification of various alcohols with acetic acid [25]. The use of biomass-bound lipase supports the binding of the water formed in the esterification process, and it is not necessary to use additional water-binding agents, e.g., molecular sieves [26]. Despite these advantages and relatively high activity of the biocatalyst, a small amount of biomass-bound lipase is obtained in one batch culture, which makes it not profitable when used on a large scale [16, 17, 27].

The use of psychrotrophic microorganisms as biocatalysts offers numerous advantages. The high microbial growth rates and the high enzymatic activities in the temperature range of $10-25^{\circ} \mathrm{C}$ may shorten the process times and minimize undesirable chemical reactions that may occur at higher temperatures [28], thus constituting considerable progress towards reduction of energy consumption.

The present paper reports for the first time that lyophilized biomass of psychrophilic fungus Chrysosporium pannorum A-1 is an efficient biocatalyst for esterification. The fungal culture conditions were successfully optimized to obtain a large amount of catalytically highly active biomass-bound lipase in one batch culture. The reaction conditions for esterification of $\beta$-citronellol and acetic acid were also optimized, and the possibility of using the biocatalyst in several reaction cycles was checked. The effect of the enzyme storage temperature on retention of the lipolytic activity of the biomass after 6 months and a year of storage was determined as well.

\section{Materials and Methods}

\section{Chemicals}

Tributyrin $(97 \%)$ and calcium carbonate $(\geq 99 \%)$ were purchased from Sigma-Aldrich, USA. (S)-(-)- $\beta$-citronellol
( $\geq 98 \%$ ) was obtained from Merck, Germany. Acetic acid ( $\geq 99.5 \%)$, n-hexane, cyclohexane, hexadecane, acetonitrile, 1,4-dioxane, chloroform, ethyl acetate, 1-propanol, N-methyl-2-pyrrolidone (NMP), dimethylacetamide (DMAC), dimethylformamide (DMF), and tetrahydrofuran at a purity of $\geq 99 \%$ were obtained from $\mathrm{POCH}$, Poland.

\section{Microorganisms and Media}

Mesophilic Rhizomucor miehei, Penicillium rhemazol, and psychrophilic Penicillium chrysogenum 9' were used as reference strains with lipolytic activity [29-31]. Chrysosporium pannorum A-1 was shown to have lipolytic activity and was used in further studies. Fungal cells were isolated from soil samples collected in the Arctic tundra from West Spitsbergen [32,33]. Prior to the experiments, the cells were maintained on malt agar slants at $4{ }^{\circ} \mathrm{C}$ and subcultured every month.

Preliminary determination of lipolytic activity was carried out on solidified agar medium (SM) composed of $0.5 \%$ butter, $0.1 \% \mathrm{~K}_{2} \mathrm{HPO}_{4}, 0.03 \% \mathrm{MgSO}_{4} \times 7 \mathrm{H}_{2} \mathrm{O}, 0.01 \%$ $\mathrm{CaCl}_{2} \times 6 \mathrm{H}_{2} \mathrm{O}, 0.2 \%\left(\mathrm{NH}_{4}\right)_{2} \mathrm{HPO}_{4}$, and $0.01 \% \mathrm{NaCl}$. Immediately before pouring onto Petri dishes, $0.15 \mathrm{~mL}$ of an alcoholic solution $(0.04 \%)$ of bromothymol blue was added as a $\mathrm{pH}$ indicator to the tubes with dissolved agar (at a temperature above $60^{\circ} \mathrm{C}$ ) to obtain a clearly green color.

In the further step of the study, liquid medium (A) composed of $1 \%$ glucose, $0.6 \% \mathrm{KH}_{2} \mathrm{PO}_{4}, 0.1 \% \mathrm{MgSO}_{4} \times 7 \mathrm{H}_{2} \mathrm{O}$, $0.4 \%$ urea, $10 \%$ olive oil, $10 \mathrm{mg} \mathrm{FeCl}{ }_{3} \times 6 \mathrm{H}_{2} \mathrm{O}, 8 \mu \mathrm{g}$ D-biotin, $200 \mu \mathrm{g}$ thiamin, and $4 \mu \mathrm{g}$ myo-inositol per liter was used. Initial $\mathrm{pH}$ was adjusted to 6.0 by adding $0.1 \mathrm{M} \mathrm{HCl}$ [31].

The culture conditions were optimized on the basal medium (BM) composed of $0.5 \%$ Tween $80,0.1 \%$ yeast extract, $0.5 \%\left(\mathrm{NH}_{4}\right)_{2} \mathrm{SO}_{4}, 0.1 \% \mathrm{~K}_{2} \mathrm{HPO}_{4}$, and $0.02 \%$ $\mathrm{MgSO}_{4} \times 7 \mathrm{H}_{2} \mathrm{O}(\mathrm{pH}=6.0$, adjusted by adding $0.1 \mathrm{M} \mathrm{HCl})$ [16]. Modified BM media were also used. They were marked as BM1 $(\mathrm{BM}+1 \%$ olive oil), $\mathrm{BM} 2(\mathrm{BM}+1 \%$ olive oil $+1 \%$ glucose), $\mathrm{BMC}\left(\mathrm{BM}+1 \% \mathrm{CaCO}_{3}\right), \mathrm{BMC} 1(\mathrm{BM} 1+1 \%$ $\left.\mathrm{CaCO}_{3}\right)$, and $\mathrm{BMC} 2\left(\mathrm{BM} 2+1 \% \mathrm{CaCO}_{3}\right)$. The optimal concentration of Tween 80 was determined using the BMC medium.

\section{Preliminary Determination of Lipolytic Activity}

The radial method was used to determine the initial lipolytic activity [34]. Discs with a diameter of $6 \mathrm{~mm}$ were cut with a sterile cork borer from malt agar plates with overgrown mycelium and then aseptically point-transferred to the SM medium. Plates with the mycelial discs on the SM medium were incubated for $24 \mathrm{~h}$ at $20^{\circ} \mathrm{C}(C$. pannorum A-1 and $P$. chrysogenum $\left.9^{\prime}\right)$ and at $30^{\circ} \mathrm{C}(R$. miehei and $P$. rhemazol). After $24 \mathrm{~h}$, the diameter of the discoloration zones in each strain was measured and expressed in $\mathrm{mm}$. Lipase secreted 
into the medium catalyzed the hydrolysis of butter fats and the release of fatty acids, which caused a decrease in $\mathrm{pH}$ and changed the color from green to yellow in the zones.

\section{Operation at a Shake Flask Scale}

To optimize culture conditions, $50 \mathrm{~mL}$ of sterile basal medium (in 300-mL Erlenmeyer flasks) with the composition depending on the experiment was uniformly inoculated with $2 \mathrm{~mL}$ of $C$. pannorum A-1 spore suspension (at a concentration of $2 \times 10^{5} \mathrm{~mL}^{-1}$ ) and cultivated at $20^{\circ} \mathrm{C}$ on a rotary shaker (150 rpm) for up to 7 days. The fungal spore suspension was prepared as an inoculum using 7-day-old spores pre-grown at $20{ }^{\circ} \mathrm{C}$ on agar slants, which were then harvested, filtered through glass wool to remove hyphal fragments, and washed twice with sterile distilled water. The spore concentration was adjusted using a hemocytometer and an Olympus BX61 light microscope.

\section{Determination of Extracellular and Intracellular Lipolytic Activity}

After completion of the culture, the mycelial biomass was separated from the post-culture liquid by centrifugation at $10,000 \mathrm{~g}$ for $15 \mathrm{~min}$ at $4{ }^{\circ} \mathrm{C}$. The supernatant was used as a source of extracellular lipase. Part of the mycelium from each culture (0.2-0.3 $\mathrm{g}$ of wet weight) was frozen for further use as a source of intracellular lipase. The rest of the biomass was dried at $105^{\circ} \mathrm{C}$ for $3 \mathrm{~h}$ to determine the dry weight of the mycelium expressed in $\mathrm{g} / \mathrm{L}$.

The determination of extracellular lipase activity was carried out on the basis of tributyrin hydrolysis using the following method: $0.5 \mathrm{~mL}$ of the supernatant was mixed with $1 \mathrm{~mL}$ of $50 \mathrm{mM}$ phosphate buffer, $\mathrm{pH} 7.0$, and $1.5 \mathrm{~mL}$ of tributyrin in a $25-\mathrm{mL}$ Erlenmeyer flask. The samples were shaken $(200 \mathrm{rpm})$ for $1 \mathrm{~h}$ at $30{ }^{\circ} \mathrm{C}$ and then $1 \mathrm{~mL}$ of $96 \%$ ethanol was added to extract free fatty acids. The concentration of the free fatty acids was determined by titration with $0.0500 \mathrm{M} \mathrm{KOH}$. Control tests with an inactivated enzyme were carried out according to the procedure described above except that the supernatant was previously boiled for $15 \mathrm{~min}$. One unit of lipase activity (U) was defined as the amount of enzyme releasing $1 \mu \mathrm{mol} \mathrm{min}{ }^{-1}$ of free fatty acids. Extracellular lipase activity was expressed as $\mathrm{U} / \mathrm{mL}$ of post-culture fluid [35].

To determine intracellular lipolytic activity, frozen mycelium was disintegrated using a potter homogenizer. The biomass was homogenized in an ice bath for 3 min with an addition of $0.5 \mathrm{~mL}$ of $50 \mathrm{mM}$ phosphate buffer. After homogenization, phosphate buffer was added to the mixture to a final volume of $5 \mathrm{~mL}$ and centrifuged at $7000 \mathrm{~g}$ for $10 \mathrm{~min}$ at $4{ }^{\circ} \mathrm{C}$ to separate mycelium residues. The supernatant was used to determine intracellular lipase activity with the same procedure as for extracellular lipase [36]. The activity of intracellular lipase was expressed as $\mathrm{U}$ per $\mathrm{mg}$ of dry weight of the mycelium.

\section{Effect of Temperature and pH on Lipase Activity}

The tributyrin hydrolysis reactions were carried out in a temperature range from 15 to $50{ }^{\circ} \mathrm{C}$ following the scheme described above. To determine the effect of $\mathrm{pH}, 0.2 \mathrm{M}$ citrate phosphate buffer ( $\mathrm{pH}$ range 2.2-8.0) and $0.2 \mathrm{M}$ carbonate buffer (pH range 9.2-10.7) were used. Hydrolysis was performed at $20^{\circ} \mathrm{C}$ [35].

\section{Preparation of the Biocatalyst for the Esterification Reaction}

Esterification was carried out using both the extracellular and intracellular enzymes of the biomass. The post-culture liquid used as a source of extracellular lipase was frozen in liquid nitrogen and then lyophilized for $24 \mathrm{~h}$. The lyophilizate was ground to powder and used in this form in the esterification reaction. The mycelial biomass used as a source of intracellular lipase was frozen at $-20^{\circ} \mathrm{C}$ overnight and next lyophilized for $24 \mathrm{~h}$. The freeze-dried biomass was milled. To study the influence of storage temperature on biocatalyst stability, both preparations were stored for a year at $-20^{\circ} \mathrm{C}$, $4{ }^{\circ} \mathrm{C}$, and $20^{\circ} \mathrm{C}$ and further used for esterification of terpene alcohol and carboxylic acid in optimal conditions.

\section{General Esterification Procedures}

The esterification reaction was carried out in sealed $25-\mathrm{mL}$ Erlenmeyer flasks equipped with magnetic stirring bars. In the standard esterification procedure, citronellol and acetic acid with an equimolar concentration $(50 \mathrm{mM})$ were dissolved in $5 \mathrm{~mL}$ of hexane containing $2 \%(\mathrm{w} / \mathrm{v})$ of the fungal biocatalyst and incubated at $40{ }^{\circ} \mathrm{C}$ for 8 or $24 \mathrm{~h}$ [16]. During other experiments, the esterification conditions depended on the optimized factors, i.e., the temperature $\left(20-70{ }^{\circ} \mathrm{C}\right)$, the amount of the biocatalyst $(1.0-3.5 \% \mathrm{w} / \mathrm{v})$, the equimolar concentration of substrates $(10-200 \mathrm{mM})$, the molar ratio of $\beta$-citronellol to acetic acid $(1: 2 ; 1: 3 ; 1: 4 ; 1: 5 ; 2: 1 ; 3: 1 ; 4: 1$; $5: 1)$, and the type of the organic solvent.

The reusability of the biomass-bound lipase from $C$. pannorum A-1 was tested in the optimal conditions of the esterification reaction. After each cycle, the reaction mixture was removed by centrifugation (7000 $g$ for $10 \mathrm{~min}$ ), and the mycelium was washed three times with $25 \mathrm{~mL}$ of $n$-hexane. Then, the biomass was dried in a desiccator and used in the next reaction cycle with fresh substrates in the same conditions. 


\section{Analysis of the Biocatalysis Efficiency}

After the specified esterification time, $50 \mu \mathrm{L}$ of the reaction mixture was taken, dried over anhydrous sodium sulfate, and diluted tenfold with $n$-hexane. The sample was subjected to GC-FID and GC-MS analyses. The GC-FID and GC-MS analyses of terpene alcohols and their esters were conducted using a DB-5 capillary column $(30 \mathrm{~m} \times 0.25 \mathrm{~mm}$ inside diameter). The separation conditions were as follows: The carrier gas was helium at a constant flow of $1 \mathrm{~mL} / \mathrm{min}$ and the injection temperature was $270{ }^{\circ} \mathrm{C}$. The oven temperature programming was as follows: $100{ }^{\circ} \mathrm{C}$ for $1 \mathrm{~min}$, which was then increased at a rate of $10{ }^{\circ} \mathrm{C} / \mathrm{min}$ to $150{ }^{\circ} \mathrm{C}$ for $1 \mathrm{~min}$ and then increased at a rate of $20{ }^{\circ} \mathrm{C} / \mathrm{min}$ to $260{ }^{\circ} \mathrm{C}$ for $1 \mathrm{~min}$. The esterification efficiency was expressed as molar conversion $(\%)$ of alcohol to ester after a specified time and as an initial ester formation rate $\left(\mu \mathrm{mol} \mathrm{mg} \mathrm{min}^{-1}\right)$. To determine the initial reaction rate, the samples were analyzed at 0.5 , $1,1.5,2,3,4,5,6,8$, and $12 \mathrm{~h}$ of the biotransformation reaction.

\section{Statistical Analysis}

The experiments were carried out in triplicate. The results were subjected to the analysis of variance (ANOVA) followed by Tukey`s post hoc test for multiple comparisons. The correlation between $\mathrm{pH}$ and extracellular and intracellular activity was analyzed based on Pearson's correlation coefficient $r$. The statistical analysis was carried out using Statistica for Windows version 13.1 (TIBCO Software Inc., Palo Alto, CA, USA). All results are presented as mean $\pm \mathrm{SEM}$ (standard error of the mean). $p<0.05$ was considered statistically significant with a confidence level of $95 \%$.

\section{Results}

The lipolytic activity of Chrysosporium pannorum A-1 was initially determined in a radial test on agar plates. The comparison of the discoloration zones with those formed by strains with confirmed lipolytic activity after 24-h incubation showed the largest zones in the $C$. pannorum A-1 (20 $\mathrm{mm}$ ) and $P$. chrysogenum $9^{\prime}$ cultures $(17 \mathrm{~mm})$. Lipolytic activity was also observed in $R$. miehei with a zone diameter of $14 \mathrm{~mm}$, whereas $P$. rhemazol showed no activity after 24-h incubation.

To optimize the culture conditions for high lipase production, the BM medium (with Tween 80, 0.5\%) was modified by adding $1 \%$ of olive oil (as a carbon source and an additional inducer of lipase synthesis) (BM1) and $1 \%$ of olive oil together with $1 \%$ of glucose (BM2). The highest extracellular lipase activity was obtained on the BM medium on the 5 th day of culture $(1.65 \pm 0.03 \mathrm{U} / \mathrm{mL})$ and on the BM1 medium on the 3rd day of culture $(1.43 \pm 0.11 \mathrm{U} / \mathrm{mL})$ (Table 1). In the case of intracellular lipase, the highest activity was observed on the BM medium on days 3 and $5(0.38 \pm 0.14$ and $0.30 \pm 0.08 \mathrm{U} / \mathrm{mg}$, respectively) and on the $3 \mathrm{rd}$ day of culture on the BM1 medium $(0.19 \pm 0.02 \mathrm{U} /$ $\mathrm{mg}$ ). A high positive correlation between $\mathrm{pH}$ and extracellular and intracellular activity was noted $(r=0.73)$ (Table 1).

The optimal temperature and $\mathrm{pH}$ were determined for the extracellular lipase activity. The highest hydrolytic activity
Table 1 Effect of the medium composition and culture duration on lipase activity and dry weight of $C$. pannorum A-1 mycelium $(\mathrm{g} / \mathrm{L})$ and $\mathrm{pH}$ of the post-culture liquid

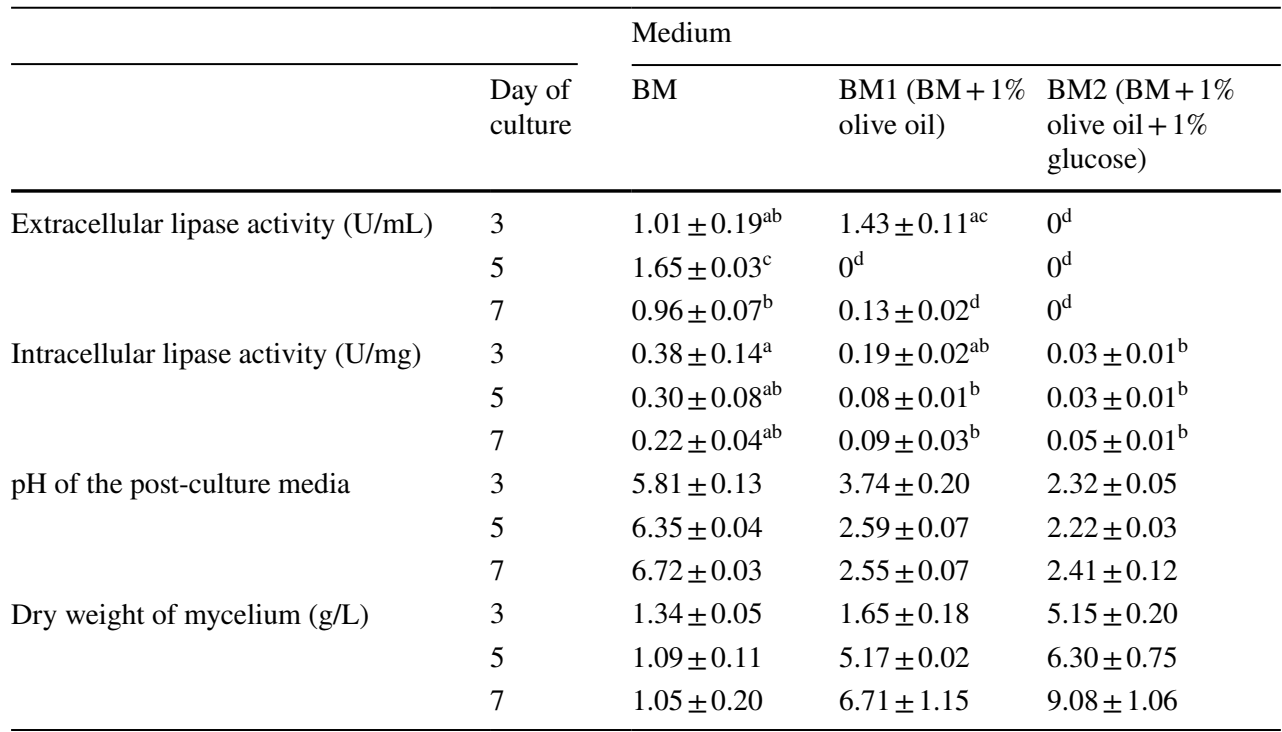

Means for the extracellular and intracellular lipase activity with different superscript letters denote a significant difference at $p<0.05$ 
was obtained at $20^{\circ} \mathrm{C}$, while the tributyrin hydrolysis efficiency at $15{ }^{\circ} \mathrm{C}$ dropped by approx. $50 \%$ (Fig. $1 \mathrm{~A}$ ). At $25^{\circ} \mathrm{C}$ and $45{ }^{\circ} \mathrm{C}$, the enzyme retained $94 \%$ and $61 \%$ of its initial activity, respectively. Lipase exhibited lipolytic activity in the range of $\mathrm{pH} 4.0-9.0$, with an optimal value of $\mathrm{pH} 7.0$ (Fig. 1B).

The addition of $1 \%$ of calcium carbonate to the media resulted in stabilization of $\mathrm{pH}$, which was kept around 6-7 on the BMC1 and BMC2 media (Table 2). This resulted in emergence of lipolytic activity on the BMC2 medium and minimum three times higher dry weight of the mycelial biomass compared to the media without $\mathrm{CaCO}_{3}$. The highest extracellular and intracellular lipolytic activity and the highest dry weight of the biomass were obtained on the 4th day of culture on BMC and BMC1.

The Tween 80 concentration was optimized in the range of $0-1 \%(\mathrm{w} / \mathrm{v})$. The highest activity was recorded on day 4 of the culture at the inducer concentration in the range of $0.4-0.9 \%$. At $0.7 \%$ Tween $80,3.70 \pm 0.79 \mathrm{U} / \mathrm{mL}$ and

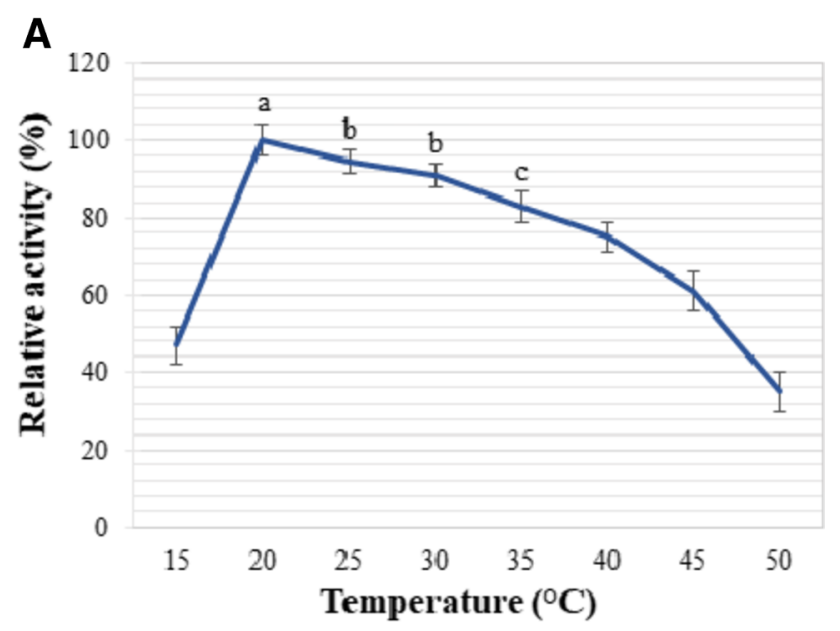

B

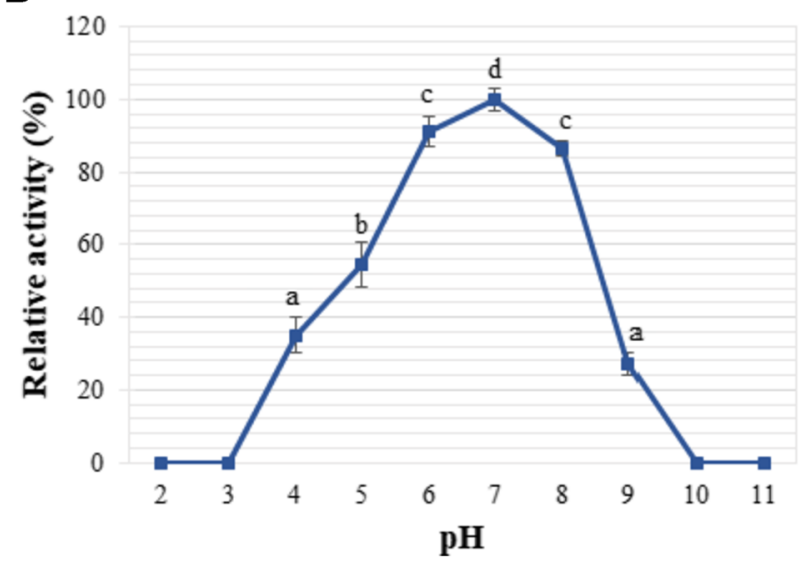

Fig. 1 Effect of temperature (A) and $\mathrm{pH}(\mathbf{B})$ on the hydrolytic activity $(\mathrm{U} / \mathrm{mL})$ of extracellular lipase from $C$. pannorum A-1. Means for the determined values with different superscript letters denote a significant difference at $p<0.05$
$0.28 \pm 0.04 \mathrm{U} / \mathrm{mg}$ of extracellular and intracellular lipase activity were recorded, respectively. The low inducer concentrations $(0.1-0.3 \%)$ resulted in the highest extracellular and intracellular lipolytic activity on day 3 (Fig. 2). The $\mathrm{pH}$ of the liquid medium was maintained at approx. 7.0 during the culture (Table 3 ).

To select the form of the fungal biocatalyst for the esterification of citronellol and acetic acid, C. pannorum A-1 was cultured on the OM medium (OM - optimal medium, i.e., BM medium with an optimal concentration of $0.7 \%$ Tween 80) in different variants for 4 days. Compared to the media without $\mathrm{CaCO}_{3}$, a sixfold to ninefold higher amount of the active mycelium biomass was obtained from the $\mathrm{OM}$ medium with the addition of calcium carbonate and/or olive oil. No esterification activity was observed when the lyophilized post-culture liquid was used. The $C$. pannorum A-1 mycelium cultured on the OM medium with addition of $1 \%$ of calcium carbonate and $1 \%$ of olive oil showed the highest biocatalytic activity (Table 4). After $8 \mathrm{~h}$ of biocatalysis in hexane at $40{ }^{\circ} \mathrm{C}, 75 \%$ molar conversion of substrate was obtained. The biomass obtained on the OM medium with addition of $1 \%$ of $\mathrm{CaCO}_{3}$ and $1 \%$ of olive oil was used to optimize the esterification of citronellol and acetic acid. A total of $78 \%$ of molar conversion was noted at $20{ }^{\circ} \mathrm{C}$ after $24 \mathrm{~h}$, while the highest molar conversion equal to $95 \%$ of the substrate to citronellyl acetate was observed at $40{ }^{\circ} \mathrm{C}$ for $24 \mathrm{~h}$, with only a slight decrease at the higher temperatures (Fig. 3A).

Over 95\% molar conversion was obtained when the substrates were used at the concentrations of $10-25 \mathrm{mM}$ (Fig. 3B). The increase in the substrate concentration from 50 up to $200 \mathrm{mM}$ was accompanied by a linear decrease in molar conversion. The maximum reaction yield (98\%) was obtained using 3\% w/v of biomass-bound lipase from $C$. pannorum A-1. The further increase in the amount of the biocatalyst did not increase efficiency (Fig. 3C).

Among the solvents used, the highest initial reaction rate and molar conversion were obtained using ethyl acetate, hexane, cyclohexane, and hexadecane (Fig. 3D). No biomass-bound lipase activity was observed when 1-butanol, DMAC, DMF, NMP, ethanol, tetrahydrofuran, and 1-propanol were used. Trace esterification activity of the biomass was obtained when acetonitrile, 1.4-dioxane, and chloroform were used. In the final optimization step, the impact of the molar ratio of the substrates on the initial reaction rate was determined. The use of excess alcohol led to an increase in the initial reaction rate of esterification of citronellol and acetic acid (Fig. 3E).

The $C$. pannorum A-1 biomass-bound lipase retained up to $70 \%$ of its initial activity after seven 24 -h reaction cycles (Fig. 4). The highest decrease in biomass activity was recorded after the fourth biocatalytic cycle. 
Table 2 Effect of addition of calcium carbonate to the culture media on lipase activity and dry weight of C. pannorum A-1 mycelium (g/L) and $\mathrm{pH}$ of the post-culture liquid

\begin{tabular}{|c|c|c|c|c|}
\hline & \multirow[b]{2}{*}{ Day of culture } & \multicolumn{3}{|l|}{ Medium } \\
\hline & & $\mathrm{BMC}\left(\mathrm{BM}+1 \% \mathrm{CaCO}_{3}\right)$ & $\begin{array}{l}\mathrm{BMC} 1(\mathrm{BMC}+1 \% \\
\text { olive oil) }\end{array}$ & $\begin{array}{l}\text { BMC2 }(\mathrm{BMC}+1 \% \\
\text { olive oil }+1 \% \text { glu- } \\
\text { cose })\end{array}$ \\
\hline \multirow[t]{4}{*}{ Extracellular lipase activity $(\mathrm{U} / \mathrm{mL})$} & 2 & $0.32 \pm 0.01$ & $0.32 \pm 0.04$ & $0.39 \pm 0.01$ \\
\hline & 3 & $1.19 \pm 0.13^{\mathrm{ab}}$ & $0.53 \pm 0.08$ & $0.42 \pm 0.1$ \\
\hline & 4 & $1.40 \pm 0.07^{\mathrm{b}}$ & $0.97 \pm 0,08^{\mathrm{a}}$ & $0.27 \pm 0.01$ \\
\hline & 5 & $0.25 \pm 0.05$ & $0.33 \pm 0.05$ & $0.25 \pm 0.05$ \\
\hline \multirow[t]{4}{*}{ Intracellular lipase activity (U/mg) } & 2 & $0.05 \pm 0.01^{\mathrm{a}}$ & $0.07 \pm 0.01^{\mathrm{ac}}$ & $0.19 \pm 0.01^{\mathrm{abcd}}$ \\
\hline & 3 & $0.10 \pm 0.01^{\mathrm{abc}}$ & $0.14 \pm 0.01^{\mathrm{abc}}$ & $0.25 \pm 0.05^{\text {bde }}$ \\
\hline & 4 & $0.24 \pm 0.01^{\text {bde }}$ & $0.37 \pm 0.02^{\mathrm{e}}$ & $0.23 \pm 0.03^{\text {bcde }}$ \\
\hline & 5 & $0.17 \pm 0.07^{\mathrm{abc}}$ & $0.34 \pm 0.04^{\mathrm{de}}$ & $0.16 \pm 0.03^{\mathrm{abc}}$ \\
\hline \multirow[t]{4}{*}{$\mathrm{pH}$ of the post-culture media } & 2 & $7.26 \pm 0.02$ & $7.22 \pm 0.07$ & $5.96 \pm 0.03$ \\
\hline & 3 & $6.92 \pm 0.04$ & $6.46 \pm 0.13$ & $5.86 \pm 0.01$ \\
\hline & 4 & $7.06 \pm 0.04$ & $5.90 \pm 0.04$ & $5.92 \pm 0.01$ \\
\hline & 5 & $7.25 \pm 0.01$ & $5.90 \pm 0.06$ & $6.07 \pm 0.02$ \\
\hline \multirow[t]{4}{*}{ Dry weight of mycelium (g/L) } & 2 & $3.44 \pm 0.11$ & $6.20 \pm 0.35$ & $16.60 \pm 0.23$ \\
\hline & 3 & $7.53 \pm 0.46$ & $8.75 \pm 0.89$ & $21.90 \pm 0.11$ \\
\hline & 4 & $7.28 \pm 0.16$ & $15.17 \pm 0.32$ & $21.80 \pm 0.11$ \\
\hline & 5 & $5.38 \pm 0.72$ & $13.75 \pm 0.09$ & $21.30 \pm 0.09$ \\
\hline
\end{tabular}

Means for the extracellular and intracellular lipase activity with different superscript letters denote a significant difference at $p<0.05$

After a year-storage period, the fungal biocatalyst lost $18 \%$ of its initial activity (Fig. 5). A significant reduction in activity was noticeable at $4{ }^{\circ} \mathrm{C}$ and $20{ }^{\circ} \mathrm{C}$ after half a year (by 32 and 36\%, respectively) and after a year of storage (by 46 and $54 \%$, respectively).

\section{Discussion}

Psychrophilic microorganisms are arousing increasing interest due to their high catalytic efficiency at low temperatures, which ensures lower energy consumption during the bioprocess [37]. Lipases from psychrophilic microorganisms facilitate efficient biocatalysis of volatile and heat-labile compounds at low temperatures [38]. For enzyme-catalyzed esterification and transesterification, commercial lipases, e.g., from Candida antarctica, are most commonly used [39, 40]. This paper presents a study on psychrophilic biomass as a new biocatalyst for direct esterification of terpene alcohols and acetic acid. In the first stage of the research, it was shown that the psychrophilic Chrysosporium pannorum A-1 strain exhibited extracellular lipolytic activity. To the best of the authors' knowledge, there is no data on the lipolytic activity of the fungus $C$. pannorum A-1. This strain has been reported to be an efficient biocatalyst for oxidative biotransformation of $\alpha$-pinene and $\beta$-pinene [32, 33, 41].
Efficient biosynthesis of enzymes is achieved in appropriately selected culture media and depends on the temperature, $\mathrm{pH}$, and culture duration. Psychrotrophic fungi are adapted to survive in cold and nutrient-poor environments [28]. The preliminary experiments on the growth of $C$. pannorum A-1 in submerged culture containing lipase inductors showed the best biomass growth rate in a temperature range of $15-20{ }^{\circ} \mathrm{C}$ but no growth at $30{ }^{\circ} \mathrm{C}$ (data not shown). The biomass production at lower temperatures offers economic benefits through energy savings, since the average temperature of the Earth's surface is about $14{ }^{\circ} \mathrm{C}$ [42]. When $C$. pannorum was cultivated on rich medium A (containing olive oil 10\%), no extracellular and intracellular lipolytic activity was detected (data not shown). However, using a $P$. chrysogenum $9^{\prime}$ strain and medium A, Bancerz et al. [31] obtained $68 \mathrm{U} / \mathrm{mL}$ of extracellular lipolytic activity. As reported by Molinari et al. [16], medium A was found to be suitable for lipase production by $C$. pannorum A-1. The presence of olive oil or a combination of olive oil and the easily assimilated carbon source (glucose) in the medium led to a significant decrease in the $\mathrm{pH}$ of the post-culture liquid along with the duration of the culture. When $\mathrm{pH}$ dropped to 3 , inhibition of the enzyme by the emerging organic acids likely occurred (Table 1). In addition, in the case of the BM2 medium, there was no lipolytic activity probably because glucose is the preferred energy source for the cell and is primarily used for biomass production. This phenomenon resembling catabolic 
Fig. 2 Effect of the Tween 80 concentration and cultivation time on the hydrolytic activity of extracellular $(\mathrm{U} / \mathrm{mL})(\mathbf{A})$ and intracellular (U/mg) (B) lipase from C. pannorum A-1. Optimization of the Tween 80 concentration was carried out for the determined values with different superscript letters denote a significant difference at $p<0.05$ on the BMC medium. Means

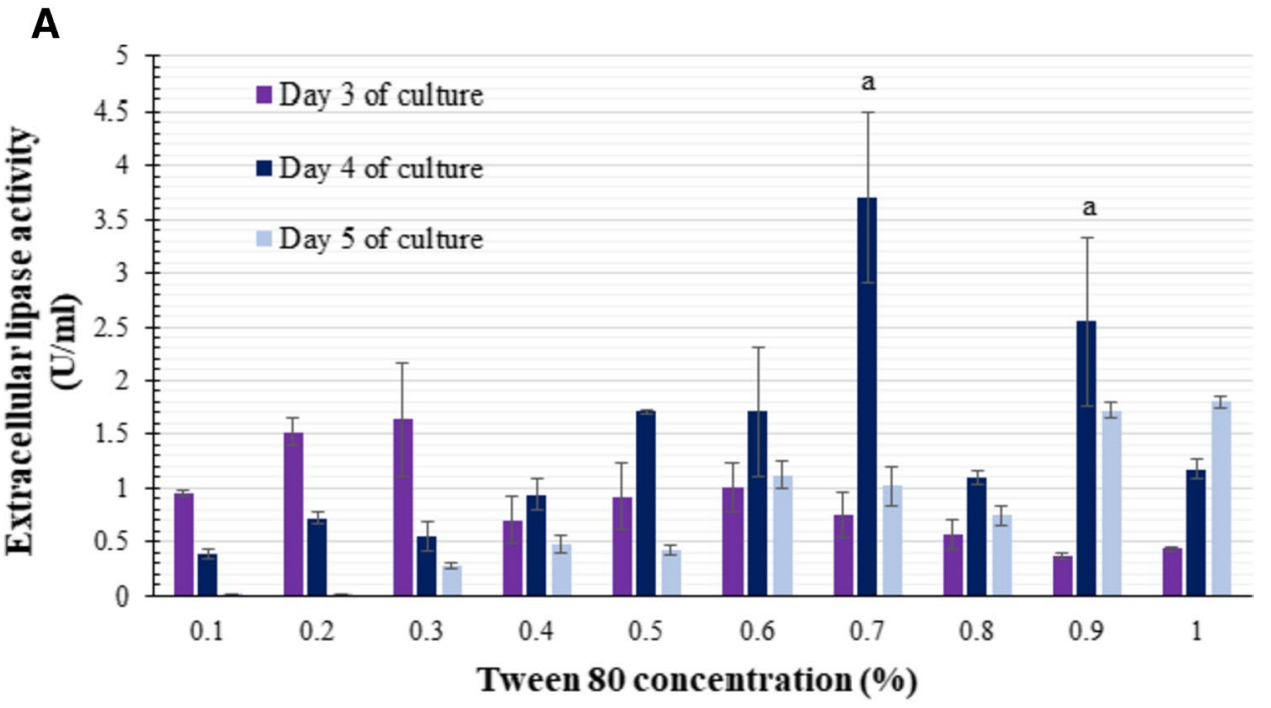

B

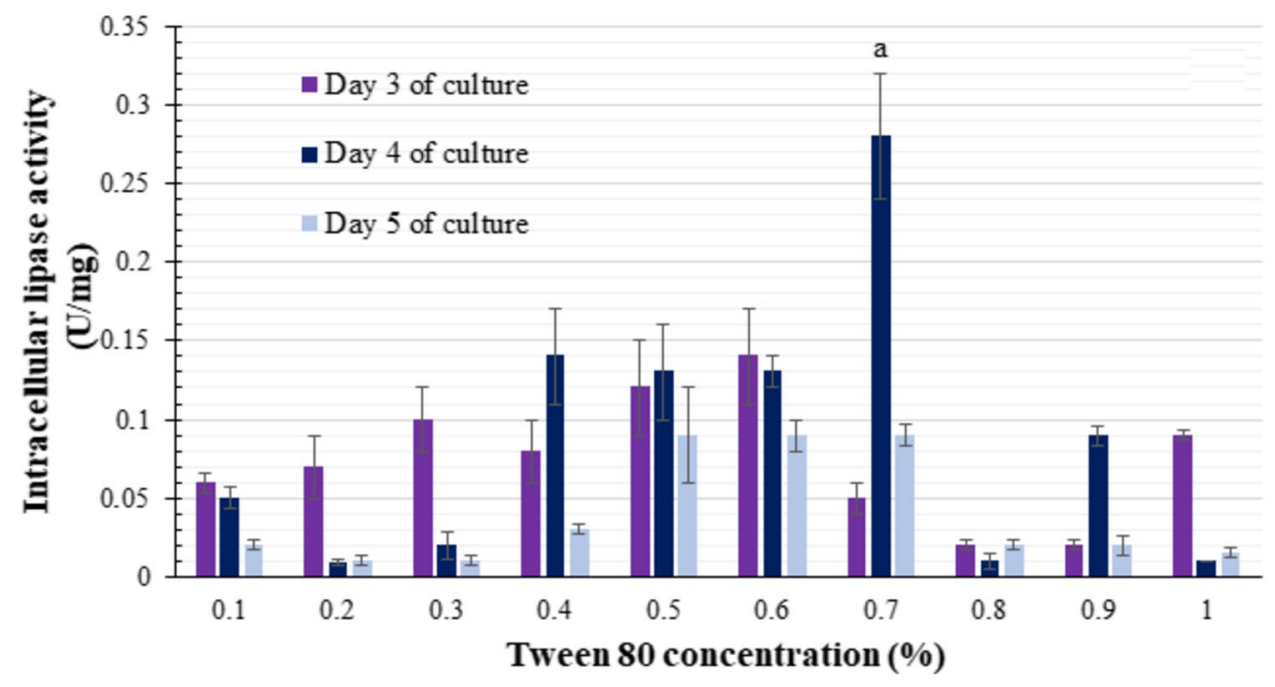

Table 3 Effect of the Tween 80 concentration on $\mathrm{pH}$ of postculture liquid and dry weight of $C$. pannorum A-1 mycelium $(\mathrm{g} / \mathrm{L})$

\begin{tabular}{|c|c|c|c|c|c|c|}
\hline \multirow[b]{3}{*}{$\begin{array}{l}\text { Tween } 80 \text { con- } \\
\text { centration (\%) }\end{array}$} & \multicolumn{3}{|c|}{$\mathrm{pH}$ of the post-culture media } & \multicolumn{3}{|c|}{ Dry weight of mycelium $(\mathrm{g} / \mathrm{L})$} \\
\hline & \multicolumn{3}{|c|}{ Day of culture } & \multicolumn{3}{|c|}{ Day of culture } \\
\hline & 3 & 4 & 5 & 3 & 4 & 5 \\
\hline 0 & $7.52 \pm 0.02$ & $7.67 \pm 0.04$ & $7.88 \pm 0.02$ & $4.22 \pm 0.11$ & $4.81 \pm 0.04$ & $2.26 \pm 0.08$ \\
\hline 0.1 & $7.52 \pm 0.01$ & $7.58 \pm 0.01$ & $7.65 \pm 0.03$ & $3.71 \pm 0.16$ & $3.51 \pm 0.07$ & $2.14 \pm 0.13$ \\
\hline 0.2 & $7.30 \pm 0.01$ & $7.43 \pm 0.03$ & $7.44 \pm 0.02$ & $4.72 \pm 0.39$ & $3.36 \pm 0.98$ & $1.08 \pm 0.08$ \\
\hline 0.3 & $7.12 \pm 0.01$ & $7.29 \pm 0.03$ & $7.33 \pm 0.03$ & $5.99 \pm 0.27$ & $3.75 \pm 0.55$ & $2.06 \pm 0.18$ \\
\hline 0.4 & $6.97 \pm 0.02$ & $7.12 \pm 0.02$ & $7.25 \pm 0.03$ & $6.74 \pm 0.12$ & $5.78 \pm 0.13$ & $3.40 \pm 0.15$ \\
\hline 0.5 & $6.84 \pm 0.01$ & $7.03 \pm 0.01$ & $7.19 \pm 0.04$ & $6.98 \pm 0.16$ & $4.85 \pm 0.55$ & $4.18 \pm 0.86$ \\
\hline 0.6 & $6.79 \pm 0.03$ & $6.96 \pm 0.04$ & $7.10 \pm 0.02$ & $6.61 \pm 0.36$ & $6.55 \pm 0.16$ & $4.83 \pm 0.20$ \\
\hline 0.7 & $6.73 \pm 0.02$ & $6.87 \pm 0.02$ & $7.07 \pm 0.02$ & $7.20 \pm 0.26$ & $5.02 \pm 0.66$ & $2.92 \pm 0.10$ \\
\hline 0.8 & $6.66 \pm 0.02$ & $6.74 \pm 0.02$ & $6.93 \pm 0.03$ & $6.43 \pm 0.41$ & $4.95 \pm 0.13$ & $4.96 \pm 0.12$ \\
\hline 0.9 & $6.66 \pm 0.02$ & $6.66 \pm 0.01$ & $6.91 \pm 0.01$ & $7.12 \pm 0.20$ & $5.09 \pm 0.17$ & $6.33 \pm 0.23$ \\
\hline 1 & $6.55 \pm 0.01$ & $6.64 \pm 0.02$ & $6.80 \pm 0.01$ & $6.02 \pm 0.17$ & $6.95 \pm 0.07$ & $5.50 \pm 0.12$ \\
\hline
\end{tabular}


Table 4 Influence of the culture medium on the biocatalytic activity of biomass-bound lipase from $C$. pannorum A-1 and the amount of its biomass obtained in one culture cycle. The culture was carried out at $20{ }^{\circ} \mathrm{C}$ for 4 days. The esterification reaction was carried out in $n$-hexane with $2 \% \mathrm{w} / \mathrm{v}$ of the biocatalyst and an equimolar $50 \mathrm{mM}$ citronellol and acetic acid concentration at $40{ }^{\circ} \mathrm{C}$ for $8 \mathrm{~h}$

\begin{tabular}{llrr}
\hline Medium & Initial reaction rate $\left(\mu \mathrm{mol} \mathrm{mg}^{-1} \mathrm{~min}^{-1}\right)$ & Reaction yield (\%) & $\begin{array}{c}\text { Dry mass of } \\
\text { mycelium } \\
(\mathrm{g} / \mathrm{L})\end{array}$ \\
\hline $\mathrm{OM}$ & & 64 & $1.56 \pm 0.21$ \\
$\mathrm{OM}+1 \%$ olive oil & $0.65 \pm 0.01^{\mathrm{a}}$ & 31 & $2.43 \pm 0.06$ \\
$\mathrm{OM}+1 \%$ olive oil $+1 \%$ glucose & $0.32 \pm 0.01^{\mathrm{b}}$ & 10 & $6.30 \pm 0.09$ \\
$\mathrm{OM}+1 \% \mathrm{CaCO}_{3}$ & $0.11 \pm 0.01^{\mathrm{c}}$ & 60 & $6.82 \pm 0.11$ \\
$\mathrm{OM}+1 \%$ olive oil $+1 \% \mathrm{CaCO}_{3}$ & $0.62 \pm 0.01^{\mathrm{a}}$ & 75 & $14.82 \pm 0.43$ \\
$\mathrm{OM}+1 \%$ olive oil $+1 \% \mathrm{CaCO}_{3}+1 \%$ glucose & $0.77 \pm 0.01^{\mathrm{d}}$ & 71 & $22.40 \pm 0.33$ \\
\hline
\end{tabular}

Means for initial reaction rate with different superscript letters denote a significant difference at $p<0.05$

OM - BM medium with optimal concentration $0.7 \%$ of Tween 80

repression can limit the use of olive oil by the cell. In turn, Falony et al. [43] obtained the highest extracellular lipase activity from Aspergillus niger on a medium composed of $2 \%$ of olive oil and $2 \%$ of glucose as a carbon source. Therefore, the medium composition should be selected individually for each microorganism and biological macromolecule.

As expected, the extracellular lipase from psychrotrophic $C$. pannorum showed the maximal activity at $20^{\circ} \mathrm{C}$; however, it was also active in a broad temperature range of $15-50{ }^{\circ} \mathrm{C}$. The results obtained in the study on the $\mathrm{pH}$ optimum of lipase activity (Fig. 1B) are consistent with the findings of earlier experiments (Table 1) and indicate that enzyme inhibition takes place at $\mathrm{pH}$ below 3 . Therefore, $\mathrm{pH}$ stabilization was used in the variant with olive oil and glucose in the medium to avoid a significant drop in $\mathrm{pH}$ during culture and thus lipase inactivation. The maintenance of the $\mathrm{pH}$ value in the optimal range for the growth of $C$. pannorum prevented lipase inhibition. This had also a positive effect on the dry weight of the mycelial biomass obtained on all three media (Table 2). Some studies have described a positive effect of $\mathrm{Ca}^{2+}$ ions increasing the biosynthesis of lipases, e.g., lipases from Bacillus cereus [44] and Penicillium camemberti [45]. However, in this study, the increase in lipase biosynthesis by $C$. pannorum A-1 does not seem to be caused directly by $\mathrm{Ca}^{2+}$ ions, because there were no significant differences in the activities between the BMC and BM media (without olive oil and glucose). The buffering property of $\mathrm{CaCO}_{3}$ was most likely essential to maintain enzyme activity on the BMC1 and $\mathrm{BMC} 2$ media (Table 2). In the case of lipase biosynthesis by $C$. pannorum A-1, Tween 80 turned out to be a better inducer than olive oil. It was found that the optimal Tween 80 concentration was strongly dependent on the cultivation time. The significant decrease in lipolytic activity observed along the culture time, especially at the low inducer concentrations $(0.1-0.3 \%)$, was probably related to the exhaustion of the inducer during prolonged cultivation. In turn, the significant decrease in mycelium biomass in the culture extended up to 5 days (Table 3 ), which was noticeable at the concentration of Tween 80 up to $0.7 \%$, may have been caused by autolysis of the fungus on the BMC medium devoid of the carbon source. Therefore, 4 culture days and a medium containing $0.7 \%$ of the inducer seem to be an optimal variant for lipase production by $C$. pannorum.

For the further study of the biocatalyst for the esterification reaction, both the post-culture liquid media and the mycelium biomass were lyophilized and used in the esterification of citronellol and acetic acid. The C. pannorum A-1 mycelium showed the highest molar conversion of the substrates to the product and the highest initial reaction rate. It is worth noting that the biocatalyst obtained from the OM medium with the addition of calcium carbonate, olive oil, and glucose was characterized by high catalytic activity and a large amount of biomass obtained in one culture cycle (Table 4). An increase in mycelium biomass obtained in one culture cycle is particularly important when the lyophilized mycelium as a biocatalyst is intended to be used on an industrial scale. As opposed to the free enzyme, the dried biomass-bound lipase shows lower sensitivity to freezing and lyophilization and higher stability in an organic solvent. The use of lyophilized biomass-bound lipase significantly reduces the costs of production of the biocatalyst, as it is possible to skip the isolation and purification of the enzyme. Esterification of citronellol and acetic acid by the biomassbound lipase from $C$. pannorum A-1 is highly efficient in the temperature range of $30-70{ }^{\circ} \mathrm{C}$ (Fig. 3A). With a temperature rise up to $70{ }^{\circ} \mathrm{C}$, the initial rate increased twofold $\left(0.58 \mu \mathrm{mol} \mathrm{mg}{ }^{-1} \mathrm{~min}^{-1}\right.$ at $70{ }^{\circ} \mathrm{C}$ vs. $0.27 \mu \mathrm{mol} \mathrm{mg}^{-1} \mathrm{~min}^{-1}$ at $20^{\circ} \mathrm{C}$ ). Increasing temperature can increase the diffusion coefficient of substrates migrating to the active sites of enzymes, thus enhancing the reaction rate [46]. Also, at higher temperatures, thermal inactivation of the enzyme may occur with the duration of the reaction. Notably, the C. pannorum biomass showed stability up to $70{ }^{\circ} \mathrm{C}$, as no 
A

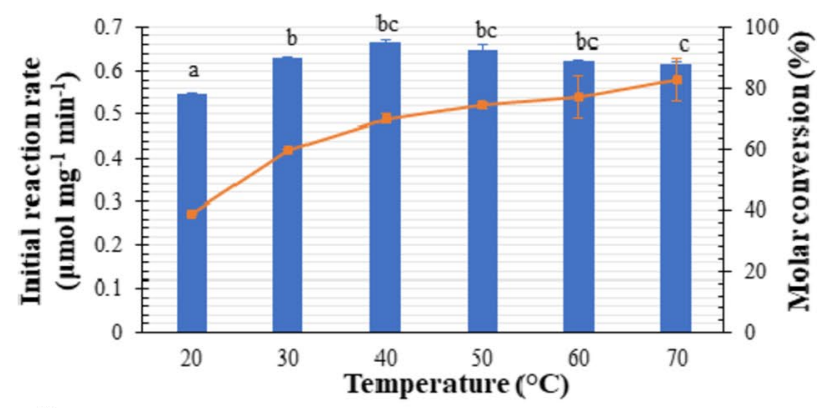

C

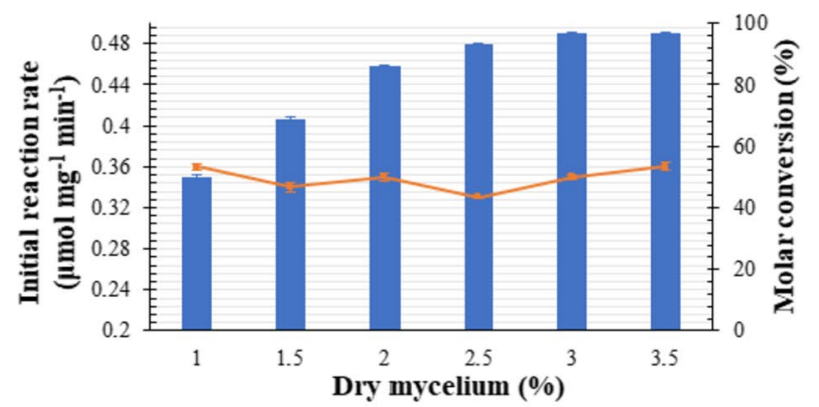

B

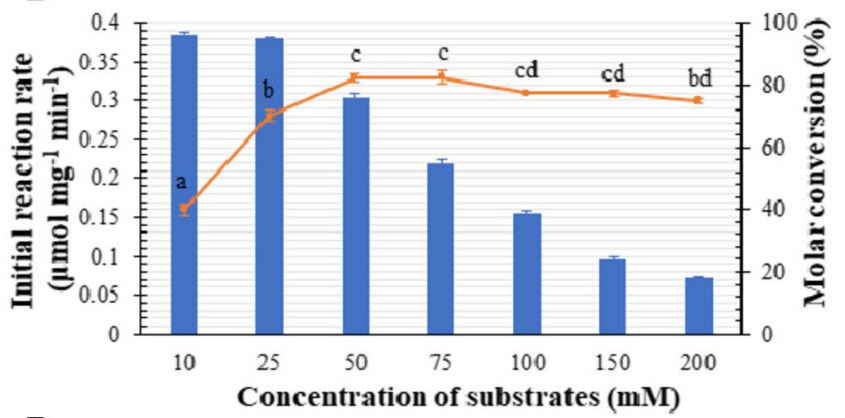

D

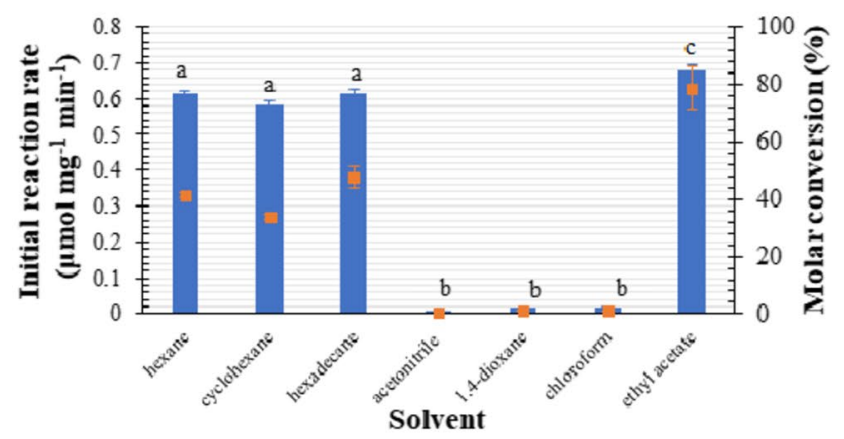

E

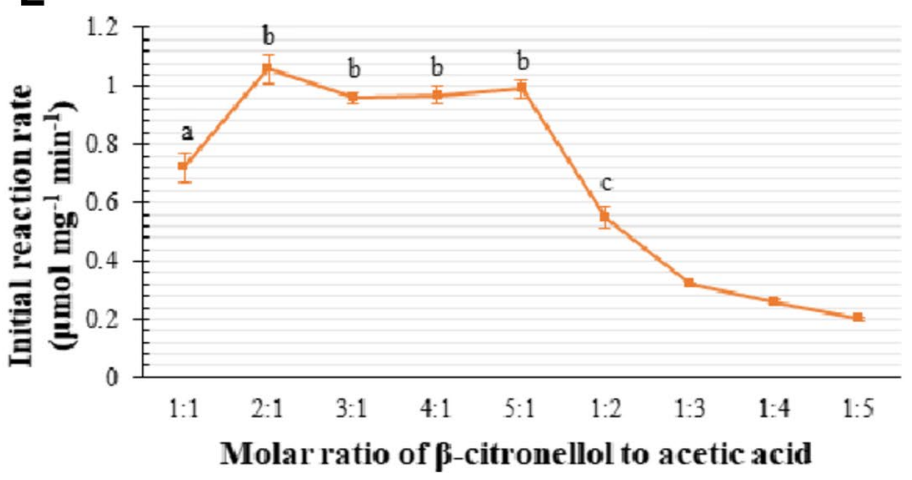

Fig. 3 Effect of temperature (A), concentration of substrates (B), amount of dry mycelium $(\mathbf{C})$, organic solvent $(\mathbf{D})$, and molar alcoholto-acid ratio (E) on the esterification reaction of $\beta$-citronellol and acetic acid catalyzed by biomass-bound lipase from $C$. pannorum A-1. The reaction was carried out in $n$-hexane with $2 \% \mathrm{w} / \mathrm{v}$ of the biocata-

statistically significant decline in molar conversion was observed in relation to $40{ }^{\circ} \mathrm{C}$. Generally, lyophilized mycelium biocatalysts are characterized by high thermostability in organic solvents $[16,27,47]$ due to the low water content in the reaction environment, which enhances enzyme denaturation [48], and the natural immobilization of the enzyme into the biomass exerting a protective effect [49]. Dry mycelium of Rhizopus oryzae was used for synthesis of different flavor esters (hexyl acetate and butyrate, geranyl acetate and butyrate). After $24 \mathrm{~h}$ of reaction in heptane at $50{ }^{\circ} \mathrm{C}$, over $95 \%$ molar conversion of geraniol to geranyl acetate was obtained [50]. In esterification of isoamyl alcohol with acetic acid by biomass-bound lipase from A. niger NCIM lyst and an equimolar $50 \mathrm{mM}$ substrate concentration for $24 \mathrm{~h}$. Bars represent the molar conversion, while the line and points in $\mathbf{D}$ indicate the initial reaction rate. Means for the determined values with different superscript letters denote a significant difference at $p<0.05$

$1207,100 \%$ conversion of the substrates was achieved in a reaction carried out in hexane at $30{ }^{\circ} \mathrm{C}$ for $96 \mathrm{~h}$ [51]. A high esterification yield (98\%) of cis-3-hexen-1-ol and acetic acid using biomass-bound lipase from Aspergillus oryzae was obtained at $70{ }^{\circ} \mathrm{C}$ [47].

In this study, the initial rate did not decrease with the increasing in the substrate concentration above $50 \mathrm{mM}$, but remained at a constant level (ca. $0.31 \mu \mathrm{mol} \mathrm{mg} \mathrm{min}^{-1}$ ). This indicates the maximum saturation of the active site of the enzyme at the concentration of $50 \mathrm{mM}$ and higher (Fig. 3B). This also implies that the catalytic activity of the biomass is inhibited by neither citronellol nor acetic acid at equimolar ratio. The results obtained in this experiment 
Fig. 4 Reusability of C. pannorum A-1 in a 24-h esterification reaction cycle. The esterification reaction was carried out in $n$-hexane at an equimolar $50 \mathrm{mM}$ citronellol and acetic acid concentration with an optimal amount of the biocatalyst at $30{ }^{\circ} \mathrm{C}$ for $24 \mathrm{~h}$. Prior to each 24-h reaction cycle, the biomass was filtered off, washed with hexane, and dried in a desiccator. Means for the determined values with different superscript letters denote a significant difference at $p<0.05$

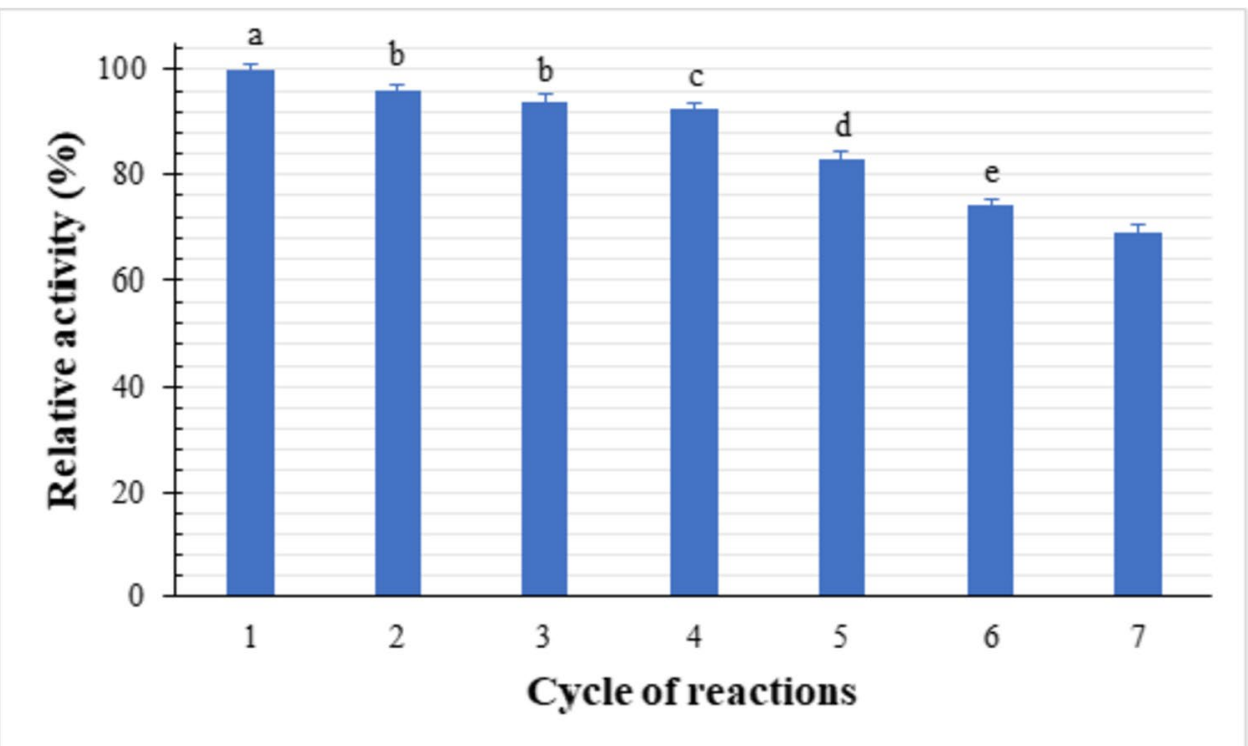

are different from other published results. An increase in the equimolar concentration of geraniol and acetic acid over $50 \mathrm{mM}$ caused a decrease in the initial reaction rate and molar conversion of substrates to geranyl acetate catalyzed by biomass-bound lipases of $A$. oryzae [16] and $R$. oryzae [27]. The authors underlined the negative impact of high acetic acid concentrations on the catalytic activity of the enzyme. In the present study, a significant decrease in enzymatic activity of the biomass was observed only when an excess of acetic acid was used (Fig. 3E). The same relationship was observed by Mhetras et al. [50] in the process of esterification of isoamyl alcohol and acetic acid by $A$. niger mycelium. Excess acid that does not participate in the reaction can cause acidification of the micro-aqueous coating of the enzyme, which leads to its inactivation. The strong influence of acetic acid on enzymatic activity was also reported by other researchers [23, 24]. As expected, the increase in the amount of the $C$. pannorum biocatalyst resulted in greater molar conversion of the substrates within $24 \mathrm{~h}$ (Fig. 3C). The initial reaction rate, i.e., approx. $0.34 \mu \mathrm{mol} \mathrm{mg}{ }^{-1} \mathrm{~min}^{-1}$, was independent of the amount of the enzyme-containing biomass. Maintenance of a constant reaction rate regardless of the amount of the biocatalyst allows a proper design of the catalysis process (selection of an appropriate substrate-biocatalyst ratio to minimize masstransfer limitation) [52]. In the case of the biomass-bound lipase from $A$. oryzae, the initial reaction rate depended on the amount of lyophilized biomass and was threefold lower at the concentration of $0.5 \% \mathrm{w} / \mathrm{v}$ than at $2 \% \mathrm{w} / \mathrm{v}$ [16].

The biomass-bound lipase from $C$. pannorum A-1 exhibited high activity of esterification of citronellol and acetic acid in the hydrophobic solvents with $\log P$ above 3.4.
Fig. 5 Effect of storage temperature on the activity of the biomass-bound lipase of $C$. pannorum A-1 in the esterification reaction of $\beta$-citronellol and acetic acid. Means for the determined values with different superscript letters denote a significant difference at $p<0.05$

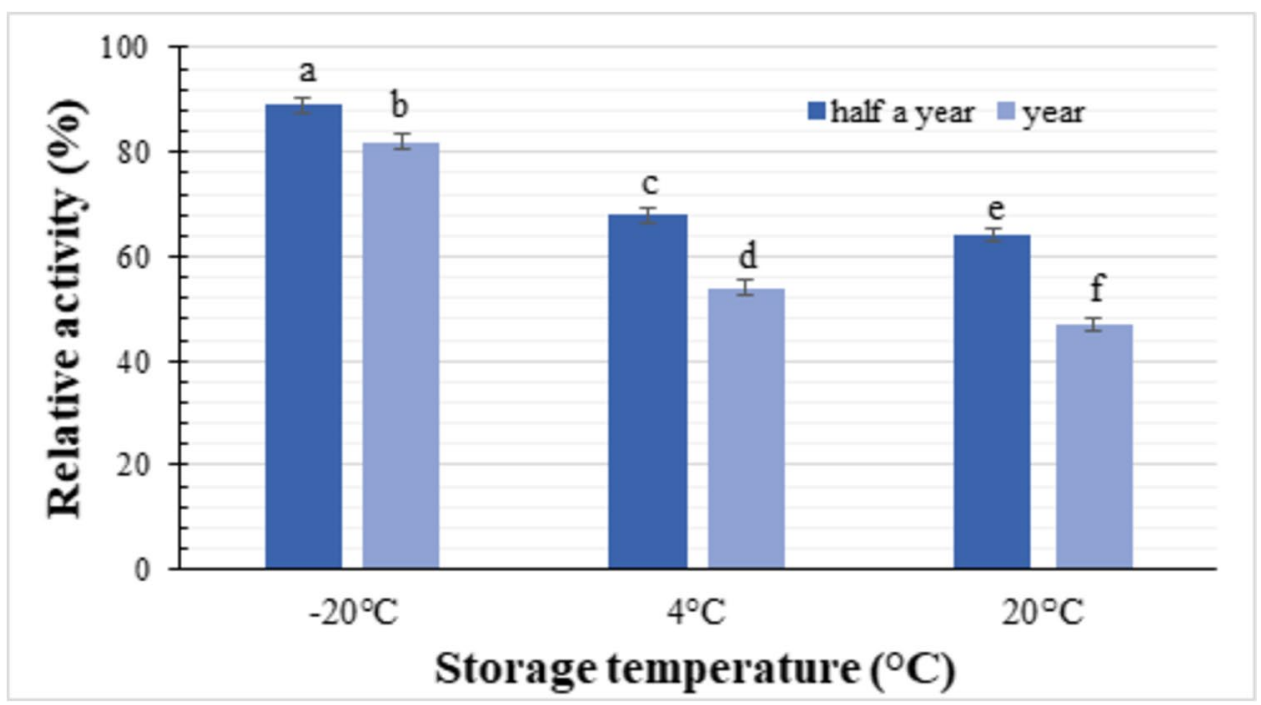


The results of these studies are consistent with the results obtained by You et al. [53]. The catalyst bioactivity is best correlated with the n-octanol-water partition coefficient $P$. Low yields are obtained when polar solvents with $\log P<2$ are used, due to the distortion of the water structure in the enzyme. In the $\log P$ range from 2 to 4 , the effect of the solvent is unpredictable, and above 4, the protein structure is intact [9]. In the variant with ethyl acetate as a solvent, transesterification by $C$. pannorum A-1 occurred instead of the esterification reaction (Fig. 3D). This was confirmed in a reaction carried out without acetic acid (data not shown). In designing a biocatalysis process with immobilized enzymes, it is very important to determine the moment of biocatalyst deactivation. In industry, the immobilized enzyme is usually replaced when the residual activity is between 50 and $10 \%$ of the initial activity [20]. Less frequent biocatalyst replacement reduces the biocatalysis costs significantly. The $C$. pannorum biomass-bound lipase was found to retain up to $80 \%$ of its initial activity after five 24-h reaction cycles (Fig. 4). Kirdi et al. [47] reported that $A$. oryzae biomass-bound lipase retained approx. $60 \%$ of activity after five 24 -h reaction cycles. The decrease in the activity of the biomass was probably caused by the filtration and drying process between the catalytic cycles and the frequent exposure to acid and alcohol. The biomass-bound lipase from C. pannorum A-1 was also characterized by high stability during storage at $-20{ }^{\circ} \mathrm{C}$. Since biocatalytic activity dropped significantly after the year-storage period at $4{ }^{\circ} \mathrm{C}$ and $20{ }^{\circ} \mathrm{C}$ (Fig. 5), it is necessary to store the preparation in a frozen state. Also, biomass-bound lipase from mesophilic Geotrichum candidum reported by Loo et. al. [17] showed a decrease in the enzyme activity to $70 \%$ of the initial activity after 8 months of storage at $4{ }^{\circ} \mathrm{C}$.

\section{Conclusions}

The $C$. pannorum A-1 biomass-bound lipase is a promising biocatalyst for efficient esterification of citronellol and acetic acid. The stabilization of $\mathrm{pH}$ with $\mathrm{CaCO}_{3}$ caused a 9.5fold increase in the biomass of the mycelium in one batch culture and a 2.4-fold increase in its biocatalytic activity. In addition, the biomass is effectively produced at temperature range of $15-20{ }^{\circ} \mathrm{C}$; hence, the cost of production of the high-performance biocatalyst can be significantly reduced. The biocatalyst is active at low temperatures, stable at relatively high temperatures, and resistant to high acetic acid concentrations in equimolar biocatalysis in hexane. Given its high performance in several biocatalytic cycles, it can be successfully used to design the process of industrially applied biocatalysis.
Author Contribution Conceptualization, M.K. and M.T.; methodology, M.K. and M.T.; software, M.K., K.B., S.M., and E.T; validation, M.K. and M.T.; formal analysis, M.K., M.T., and K.B.; investigation, M.K. and K.B.; resources, M.K. and M.T.; data curation, M.K., E.T., and S.M.; writing-original draft preparation, M.K. and M.T.; writing-review and editing, M.K., M.T., and K.B.; visualization, M.K. and K.B.; supervision, M.T.; project administration, M.K. and M.T.; funding acquisition, M.K. and M.T. All authors have read and approved the manuscript.

Funding The authors received institutional funds from Maria CurieSkłodowska University in Lublin, Poland to support this work.

Data Availability All relevant data are within the paper.

\section{Declarations}

Conflict of Interest The authors declare no competing interests.

Open Access This article is licensed under a Creative Commons Attribution 4.0 International License, which permits use, sharing, adaptation, distribution and reproduction in any medium or format, as long as you give appropriate credit to the original author(s) and the source, provide a link to the Creative Commons licence, and indicate if changes were made. The images or other third party material in this article are included in the article's Creative Commons licence, unless indicated otherwise in a credit line to the material. If material is not included in the article's Creative Commons licence and your intended use is not permitted by statutory regulation or exceeds the permitted use, you will need to obtain permission directly from the copyright holder. To view a copy of this licence, visit http://creativecommons.org/licenses/by/4.0/.

\section{References}

1. De Oliveira FL, De Oliveira AM, Bicas JL (2017) Bioaromasperspectives for sustainable development. Trends Food Sci Tech. https://doi.org/10.1016/j.tifs.2017.02.005

2. Costa VV, Da Silva Rocha KA, Oliveira LCA, Kozhevnikova EF, Kozhevnikovc IV, Gusevskaya EV (2016) Heteropoly acid catalysts for the synthesis of fragrance compounds from bio-renewables: acetylation of nopol and terpenic alcohols. RSC Adv. https:// doi.org/10.1039/C6RA02266A

3. Perdomo IC, Contente ML, Pinto A, Romano D, Fernandes P, Molinari F (2020) Continuous preparation of flavour-active acetate esters by direct biocatalytic esterification. Flavour Fragr J. https://doi.org/10.1002/ffj.3552

4. Olsen T, Kerton F, Marriott R, Grogan G (2006) Biocatalytic esterification of lavandulol in supercritical carbon dioxide using acetic acid as the acyl donor. Enzyme Microb Technol. https://doi. org/10.1016/j.enzmictec.2005.11.025

5. Lozano P, Piamtongkam R, Kohns K, De Diego T, Valtier M, Iborra JL (2007) Ionic liquids improve citronellyl ester synthesis catalyzed by immobilized Candida antarctica lipase B in solventfree media. Green Chem. https://doi.org/10.1039/B617444B

6. Gupta C, Prakash D, Gupta SA (2015) A biotechnological approach to microbial based perfumes and flavours. J Microb Exp. https://doi.org/10.15406/jmen.2015.02.00034

7. Matsumoto T, Yamada R, Ogino H (2019) Chemical treatments for modification and immobilization to improve the solventstability of lipase. World J Microb Biot. https://doi.org/10.1007/ s11274-019-2777-8 
8. Thangaraj B, Solomon PR (2019) Immobilization of lipases-a review part I: enzyme immobilization. Chem Bio Eng Rev. https:// doi.org/10.1002/cben.201900016

9. Kumar A, Dhar K, Kanwar SS, Arora PK (2016) Lipase catalysis in organic solvents: advantages and applications. Biol Proced Online. https://doi.org/10.1186/s12575-016-0033-2

10. Adlercreutz P (2013) Immobilisation and application of lipases in organic media. Chem Soc Rev. https://doi.org/10.1039/C3CS3 $5446 \mathrm{~F}$

11. Mehta A, Bodh U, Gupta R (2017) Fungal lipases: a review. J Biotech R 8:58-77

12. Converti A, Del Borghia A, Gandolfi R, Molinari F, Palazzia E, Peregoa P, Zillia M (2002) Simplified kinetics and thermodynamics of geraniol acetylation by lyophilized cells of Aspergillus oryzae. Enzyme and Microb Technol. https://doi.org/10.1016/ S0141-0229(01)00481-1

13. Arcens D, Grau E, Grelier S, Cramail H, Peruch F (2020) Impact of fatty acid structure on CALB-catalyzed esterification of glucose. Eur J Lipid Sci Technol. https://doi.org/10.1002/ejlt.20190 0294

14. Pedersen JN, Liu S, Zhou Y, Balle T, Xu X, Guo Z (2020) Synergistic effects of binary ionic liquid-solvent systems on enzymatic esterification of esculin. Food Chem. https://doi.org/10.1016/j. foodchem.2019.125858

15. Bharathi D, Rajalakshmi G (2019) Microbial lipases: an overview of screening, production and purification. Biocatal Agric Biotechnol. https://doi.org/10.1016/j.bcab.2019.101368

16. Molinari F, Gandolfi R, Converti A, Zilli M (2000) Myceliumbound carboxylesterase from Aspergillus oryzae: an efficient catalyst for acetylation in organic solvent. Enzyme Microb Technol. https://doi.org/10.1016/s0141-0229(00)00263-5

17. Loo JL, Khoramnia A, Lai OM, Long K, Ghazali HM (2014) Mycelium-bound lipase from a locally isolated strain of Geotrichum candidum. Molecules. https://doi.org/10.3390/molecules1 9068556

18. Colin VL, Baigorí MD, Pera LM (2011) Mycelium-bound lipase production from Aspergillus niger MYA 135, and its potential applications for the transesterification of ethanol. J Basic Microbiol. https://doi.org/10.1002/jobm.201000232

19. Hassan ME, Yang Q, Xiao Z, Liu L, Wang N, Cui X, Yang L (2019) Impact of immobilization technology in industrial and pharmaceutical applications. 3 Biotech. https://doi.org/10.1007/ s13205-019-1969-0

20. Basso A, Serban S (2019) Industrial applications of immobilized enzymes-a review. Mol Catal. https://doi.org/10.1016/j.mcat. 2019.110607

21. Stergiou PY, Foukis A, Filippou M, Koukouritaki M, Parapouli M, Theodorou LG, Hatziloukas E, Afendra A, Pandey A, Papamichael EM (2013) Advances in lipase-catalyzed esterification reactions. Biotechnol Adv. https://doi.org/10.1016/j.biotechadv.2013. 08.006

22. Castro HF, Oliveira PC, Pereira EB (1997) Evaluation of different approaches for lipase catalysed synthesis of citronellyl acetate. Biotechnol Lett. https://doi.org/10.1023/A:1018349406159

23. Guvenc A, Kapucu N, Mehmetoglu U (2003) Optimization of the enzymatic production of isoamyl acetate with Novozyme 435 from Candida antarctica. Chem Eng Commun. https://doi.org/10. 1080/00986440302124

24. Romero MD, Calvo L, Alba C, Deneshfar A, Ghaziaskar HS (2007) A kinetic study of isoamyl acetate synthesis by immobilized lipase-catalyzed acetylation in $n$-hexane. J Biotechnol. https://doi.org/10.1016/j.jbiotec.2006.07.009

25. Liu KJ, Huang YR (2010) Lipase-catalyzed production of a bioactive terpene ester in supercritical carbon dioxide. J Biotechnol. https://doi.org/10.1016/j.jbiotec.2010.02.017
26. Tamborini L, Romano D, Pinto A, Contente M, Iannuzzi MC, Conti P, Molinari F (2013) Biotransformation with whole microbial systems in a continuous flow reactor: resolution of $(R S)$-flurbiprofen using Aspergillus oryzae by direct esterification with ethanol in organic solvent. Tetrahedron Lett. https://doi.org/10. 1016/j.tetlet.2013.08.119

27. Molinari F, Marianelli G, Aragozzini F (1995) Production of flavor esters by Rhizopus oryzae. Appl Microbiol Biotechnol. https:// doi.org/10.1007/BF00166910

28. Duarte AWF, dos Santos JA, Vianna MV, Vieira JMF, Mallagutti VH, Inforsato FJ, Wentzel LCP, Lario LD, Rodrigues A, Pagnocca FC, Junior AP, Sette LD (2018) Cold-adapted enzymes produced by fungi from terrestrial and marine Antarctic environments. Crit Rev Biotechnol. https://doi.org/10.1080/07388551.2017.1379468

29. Rodrigues RC, Fernandez-Lafuente R (2010) Lipase from Rhizomucor miehei as an industrial biocatalyst in chemical process. J Mol Catal B Enzym. https://doi.org/10.1016/j.molcatb.2010.02. 003

30. Eitenmiller RR, Vakil JR, Shani KM (1970) Production and properties of Penicillium roqueforti lipase. J Food Sci. https://doi.org/ 10.1111/j.1365-2621.1970.tb12121.x

31. Bancerz R, Ginalska G, Fiedurek J, Gromada A (2005) Cultivation conditions and properties of extracellular crude lipase from the psychrotrophic fungus Penicillium chrysogenum 9'. J Ind Microbiol Biotechnol. https://doi.org/10.1007/s10295-005-0235-0

32. Trytek M, Jędrzejewski K, Fiedurek J (2015) Bioconversion of $\alpha$-pinene by a novel cold-adapted fungus Chrysosporium pannorum. J Ind Microbiol Biotechnol. https://doi.org/10.1007/ s10295-014-1550-0

33. Kutyła M, Fiedurek J, Gromada A, Jędrzejewski K, Trytek M (2020) Mutagenesis and adaptation of the psychrotrophic fungus Chrysosporium pannorum A-1 as a method for improving $\beta$-pinene bioconversion. Molecules. https://doi.org/10.3390/molec ules 25112589

34. Shelley AW, Deeth HC, MacRae IC (1987) A numerical taxonomic study of psychrotrophic bacteria associated with lipolytic spoilage of raw milk. J Appl Bacteriol. https://doi.org/10.1111/j. 1365-2672.1987.tb02399.x

35. Ginalska G, Bancerz R, Korniłowicz-Kowalska T (2004) A thermostable lipase produced by a newly isolated Geotrichum like strain, R59. J Ind Microbiol Biotechnol. https://doi.org/10.1007/ s10295-004-0134-9

36. De Araujo AA, Roussos S (2002) A technique for mycelial development of ectomycorrhizal fungi on agar media. Appl Biochem Biotechnol. https://doi.org/10.1385/ABAB:98-100:1-9:311

37. Li M, Yang LR, Xu G, Wu JP (2013) Screening, purification and characterization of a novel cold-active and organic solvent-tolerant lipase from Stenotrophomonas maltophilia CGMCC 4254. Bioresour Technol. https://doi.org/10.1016/j.biortech.2013.08.101

38. De Pascale D, Cusano AM, Autore F, Parrilli E, Di Prisco G, Marino G, Tutino ML (2008) The cold-active Lip1 lipase from the Antarctic bacterium Pseudoalteromonas haloplanktis TAC125 is a member of a new bacterial lipolytic enzyme family. Extremophiles. https://doi.org/10.1007/s00792-008-0163-9

39. Da SilvaCorrea L, Henriques RO, Rios JV, Lerin LA, de Oliveira D, Furigo A (2020) Lipase-catalyzed esterification of geraniol and citronellol for the synthesis of terpenic esters. Appl Biochem Biotechnol. https://doi.org/10.1007/s12010-019-03102-1

40. Shahedi M, Yousefi M, Habibi Z, Mohammadi M, As'habi MA (2019) Co-immobilization of Rhizomucor miehei lipase and Candida antarctica lipase $B$ and optimization of biocatalytic biodiesel production from palm oil using response surface methodology. Renew Energy. https://doi.org/10.1016/j.renene.2019.04.042

41. Trytek M, Fiedurek J, Gromada A (2016) Effect of some abiotic stresses on the biotransformation of $\alpha$-pinene by a psychrotrophic 
Chrysosporium pannorum. Biochem Eng J. https://doi.org/10. 1016/j.bej.2016.03.010

42. Hossain MF (2019) Chapter two-environment. In: Hossain MF (ed) Sustainable design and build. Butterworth-Heinemann, Oxford, pp 11-66

43. Falony G, Armas JC, Mendoza JCD, Hernandez JLM (2006) Production of extracellular lipase from Aspergillus niger by solidstate fermentation. Food Technol Biotechnol 44:235-240

44. Mazhar H, Abbas N, Zamir T, Hussain Z, Ali SS (2018) Optimization study of lipolytic enzyme from Bacillus cereus, PCSIR NL-37. Punjab Univ J Zool. https://doi.org/10.17582/journal.pujz/ 2018.33.2.217.224

45. Boratyński F, Szczepańska E, Grudniewska A, Gniłka R, Olejniczak T (2018) Improving of hydrolases biosythesis by solid-state fermentation of Penicillium camemberti on rapeseed cake. Sci Rep. https://doi.org/10.1038/s41598-018-28412-y

46. Varma MN, Madras G (2008) Kinetics of synthesis of butyl butyrate by esterification and transesterification in supercritical carbon dioxide. J Chem Technol Biotechnol. https://doi.org/10. $1002 /$ jctb. 1897

47. Kirdi R, Akacha NB, Bejaoui H, Messaoudi Y, Romano D, Molinari F, Gargouri M (2017) Mycelium-bound lipase from Aspergillus oryzae as an efficient biocatalyst for cis-3-hexen-1-yl acetate synthesis in organic solvent. Biocatal Agric Biotechnol. https:// doi.org/10.1016/j.bcab.2017.01.009
48. Claon PA, Akoh CC (1994) Effect of reaction parameters on SP435 lipase-catalysed synthesis of citronellyl acetate on organic solvent. Enzyme Microb Technol. https://doi.org/10.1016/01410229(94)90056-6

49. Gandhi NN, Patil NS, Sawant SB, Joshi JB (2000) Lipase-catalyzed esterification. Catal Rev Sci Eng. https://doi.org/10.1081/ CR-100101953

50. Gandolfi R, Converti A, Pirozzi D, Molinari F (2001) Efficient and selective microbial esterification with dry mycelium of Rhizopus oryzae. J Biotechnol. https://doi.org/10.1016/s0168-1656(01) 00345-5

51. Mhetras N, Patil S, Gokhale D (2010) Lipase of Aspergillus niger NCIM 1207: a potential biocatalyst for synthesis of isoamylacetate. Indian J Microbiol. https://doi.org/10.1007/ s12088-011-0087-4

52. Gomes MD, Woodley JM (2019) Considerations when measuring biocatalyst performance. Molecules. https://doi.org/10.3390/ molecules24193573

53. You P, Su E, Yang X, Mao D, Wei D (2011) Carica papaya lipase catalyzed synthesis of terpene esters. J Mol Catal B Enzym. https://doi.org/10.1016/j.molcatb.2011.04.012

Publisher's Note Springer Nature remains neutral with regard to jurisdictional claims in published maps and institutional affiliations. 